\title{
The influence of eruption season on the global aerosol evolution and radiative impact of tropical volcanic eruptions
}

\author{
M. Toohey ${ }^{1,{ }^{*},}$ K. Krüger ${ }^{1}$, U. Niemeier ${ }^{2}$, and C. Timmreck ${ }^{2}$ \\ ${ }^{1}$ Leibniz Institute of Marine Sciences (IFM-GEOMAR), Kiel, Germany \\ ${ }^{2}$ Max Planck Institute for Meteorology, Hamburg, Germany \\ *Invited contribution by M. Toohey, recipient of the EGU Young Scientists' Outstanding Poster Presentation Award 2010
}

Received: 21 June 2011 - Published in Atmos. Chem. Phys. Discuss.: 8 August 2011

Revised: 1 November 2011 - Accepted: 24 November 2011 - Published: 9 December 2011

\begin{abstract}
Simulations of tropical volcanic eruptions using a general circulation model with coupled aerosol microphysics are used to assess the influence of season of eruption on the aerosol evolution and radiative impacts at the Earth's surface. This analysis is presented for eruptions with $\mathrm{SO}_{2}$ injection magnitudes of 17 and $700 \mathrm{Tg}$, the former consistent with estimates of the $1991 \mathrm{Mt}$. Pinatubo eruption, the later a near"super eruption". For each eruption magnitude, simulations are performed with eruptions at $15^{\circ} \mathrm{N}$, at four equally spaced times of year. Sensitivity to eruption season of aerosol optical depth (AOD), clear-sky and all-sky shortwave (SW) radiative flux is quantified by first integrating each field for four years after the eruption, then calculating for each cumulative field the absolute or percent difference between the maximum and minimum response from the four eruption seasons. Eruption season has a significant influence on AOD and clear-sky SW radiative flux anomalies for both eruption magnitudes. The sensitivity to eruption season for both fields is generally weak in the tropics, but increases in the mid- and high latitudes, reaching maximum values of $\sim 75 \%$. Global mean AOD and clear-sky SW anomalies show sensitivity to eruption season on the order of 15-20\%, which results from differences in aerosol effective radius for the different eruption seasons. Smallest aerosol size and largest cumulative impact result from a January eruption for Pinatubomagnitude eruption, and from a July eruption for the nearsuper eruption. In contrast to AOD and clear-sky SW anomalies, all-sky SW anomalies are found to be insensitive to sea-
\end{abstract}

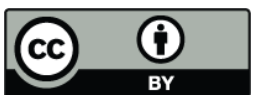

Correspondence to: $\mathrm{M}$. Toohey (mtoohey@ifm-geomar.de) son of eruption for the Pinatubo-magnitude eruption experiment, due to the reflection of solar radiation by clouds in the mid- to high latitudes. However, differences in all-sky SW anomalies between eruptions in different seasons are significant for the larger eruption magnitude, and the $\sim 15 \%$ sensitivity to eruption season of the global mean all-sky SW anomalies is comparable to the sensitivity of global mean AOD and clear-sky SW anomalies. Our estimates of sensitivity to eruption season are larger than previously reported estimates: implications regarding volcanic AOD timeseries reconstructions and their use in climate models are discussed.

\section{Introduction}

Volcanic sulfate aerosols resulting from the injection of sulfur into the stratosphere by explosive volcanic eruptions can have a significant impact on the global Earth system. These aerosols reflect solar visible radiation, causing cooling at the Earth's surface, and absorb solar near-infrared and terrestrial infrared radiation, causing warming of the stratosphere (e.g., Robock, 2000).

Volcanic eruptions in the tropics have stronger climate impacts than comparable eruptions at mid- or high latitudes, since the large-scale circulation pattern of the stratosphere, or Brewer-Dobson circulation (BDC) leads to longer stratospheric lifetimes and the possibility of global coverage for volcanic aerosols introduced into the tropical stratosphere (Hamill et al., 1997). The Brewer-Dobson circulation is generally characterized by upward motion in the tropics, poleward motion and mixing in the midlatitudes, and downward motion at polar latitudes (e.g., Holton et al., 1995).

Published by Copernicus Publications on behalf of the European Geosciences Union. 
This circulation is driven by the breaking of planetary-scale Rossby waves in the midlatitude stratosphere (McIntyre and Palmer, 1983), which occurs predominantly in the winter hemisphere since these waves cannot propagate upward through the easterly winds of the summer hemisphere (Charney and Drazin, 1961). As a result, transport out of the tropical stratosphere (Waugh, 1996), poleward meridional mass transport (Rosenlof, 1995) and two-way mixing in the midlatitudes occurs most strongly in the winter hemisphere, resulting in a seasonal cycle in the BDC.

Post-eruption aerosol evolution (at least in terms of the spatial distribution of the aerosol cloud) is largely controlled by atmospheric transport, and is thus a function of the specific meteorological conditions at the time of eruption. However, some level of explanation of aerosol evolution can be taken from the mean seasonal cycle of the BDC. Knowledge of the seasonal cycle of the BDC and related aerosol transport has been used to reconstruct volcanic forcing data sets from historical records for use in climate reconstruction modeling. For example, Ammann et al. (2003) introduced a latitudinally varying, monthly mean aerosol optical depth (AOD) reconstruction using a simple scheme with parameterized seasonally varying stratospheric meridional aerosol transport and removal. Such a reconstruction should serve as a more realistic input in climate models than, for example, a global or hemispheric mean timeseries. Gao et al. (2008) used a similar transport and removal scheme to produce a latitudinally varying volcanic forcing data set based on ice core sulfate records which covers the last $1500 \mathrm{yr}$. Since the seasons of eruption for most of the volcanic events over this time period are unknown, Gao et al. (2008) quantified the impact of an unknown season of eruption on their reconstruction method. Using the parameterized transport scheme, they found only very small differences (maximum $3 \%$ ) between the time-averaged aerosol burdens for Tambora-like eruptions in different seasons, although they also noted that general circulation model (GCM) studies would be necessary to test the detailed radiative, and dynamic responses associated with eruptions in different seasons.

Kravitz and Robock (2011) have performed GCM simulations of volcanic aerosol evolution from high latitude Northern Hemisphere eruptions, and found that season of eruption is important in determining the radiative impact due to the seasonal variation in solar insolation at high latitudes, and seasonal variations in the rate of removal of aerosols from the high latitude stratosphere. The simulations described by Kravitz and Robock (2011) were of eruptions of $1.5-5 \mathrm{Tg}$ $\mathrm{SO}_{2}$ injection, and were performed using aerosols of prescribed dry radius.

This work aims to quantify the influence of eruption season on the impact of tropical volcanic eruptions using a detailed GCM with coupled aerosol microphysics. Specifically, we aim to address the following questions:
1. How does season of eruption influence the resulting AOD, in terms of its global mean and zonal mean evolution?

2. How does season of eruption impact the resulting anomalies in solar shortwave (SW) radiative flux at the surface, and is the sensitivity of surface SW radiative flux to eruption season the same as that for AOD?

3. How does the sensitivity to eruption season of AOD and SW anomalies change for eruptions of different stratospheric sulfur injection magnitudes?

In order to address these questions, we have performed ensemble simulations for eruptions on the first day of January, April, July, and October, for eruptions of two magnitudes, with stratospheric $\mathrm{SO}_{2}$ injections of 17 and $700 \mathrm{Tg}$. The smaller injection magnitude is consistent with estimates of the June 1991 Mt. Pinatubo eruption (Guo, 2004a). Our simulations of this magnitude eruption thus can be considered as roughly addressing the question of how the impact of Pinatubo might have changed had it erupted in a different time of year. The larger injection magnitude is roughly 40 times that of Pinatubo, and is nearly as large as the approximately-defined $800 \mathrm{Tg}$ lower limit for $\mathrm{SO}_{2}$ injection by a "super-eruption" (Self, 2006). Examining such a large eruption magnitude allows us to explore how global aerosol transport, and its dependence on season, changes for eruptions where aerosol heating significantly perturbs stratospheric dynamics.

The paper is organized as follows: Sect. 2 describes the model and the simulations used in this study. Section 3 contains a comparison of observations of perturbed conditions resulting from the 1991 Pinatubo eruption with Pinatubomagnitude eruption simulations, and tests the impact of eruption longitude on the model simulations. In Sect. 4, we quantify the sensitivity of the model simulated aerosol optical depth and surface radiative anomalies to season of eruption for the two eruption magnitudes introduced above. Conclusions are given in Sect. 5.

\section{Method}

\subsection{Model description}

The study was performed using the coupled aerosol-GCM MAECHAM5-HAM (Niemeier et al., 2009). MAECHAM5 (Giorgetta et al., 2006) is a middle atmosphere version of the ECHAM5 GCM (Roeckner et al., 2003). The model solves prognostic equations for vorticity, divergence, surface pressure and temperature, expressed in terms of spherical harmonics with a triangular truncation. Trace components, including $\mathrm{SO}_{2}$ and aerosols, are transported with a flux form semi-Lagrangian transport scheme (Lin and Rood, 1996). ECHAM5 radiation is based on the six band $(1.85-4 \mu \mathrm{m}) \mathrm{SW}$ 
radiative transfer scheme of Fouquart and Bonnel (1980), and the RRTM (Rapid Radiative Transfer Model) 16 band (3.3$100 \mu \mathrm{m}$ ) longwave radiation scheme (Mlawer et al., 1997). It considers the absorption of greenhouse gases $\left(\mathrm{CO}_{2}, \mathrm{CH}_{4}\right.$ $\mathrm{H}_{2} \mathrm{O}, \mathrm{O}_{3}$, and CFCs) as well as scattering and absorption by clouds and aerosols. For the radiation calculations concerning volcanic aerosols, optical parameters are calculated online from the time dependent aerosol mass mixing ratio and normalized optical parameters (extinction, absorption coefficients, and asymmetry factor).

MAECHAM5 is used here in a free-running climate mode, with T42 spectral truncation and 39 vertical levels up to $0.01 \mathrm{hPa}$. At this model resolution, the model has no quasibiennial oscillation (QBO): in control simulations, equatorial stratospheric winds are easterly throughout the year. Sea surface temperatures (SSTs) are an annually repeating monthly mean climatology based on the Atmospheric Model Intercomparison Project SST observational data set (Hurrell et al., 2008). As a result, simulated surface temperature response to volcanic aerosols is largely damped, however, this should have no direct impact on the degree to which the volcanic aerosol modify incoming solar radiation. Greenhouse gases are set to represent modern conditions.

Model processes related to sulfate aerosols are calculated by the aerosol microphysical module HAM (Stier et al., 2005), which is interactively coupled to MAECHAM5. HAM has been adopted for stratospheric conditions (as well as for high $\mathrm{SO}_{2}$ concentrations) as outlined by Niemeier et al. (2009). Changes to M7, the microphysical core of HAM (Vignati, 2004), were performed according to boxmodel studies for large volcanic eruptions (Kokkola et al., 2009). Volcanic simulations with the MAECHAM5-HAM model are initiated by injecting $\mathrm{SO}_{2}$ directly into the lower stratosphere into a model gridbox corresponding to the volcano's geographical location, and the model layer corresponding to the pressure height level of $30 \mathrm{hPa}(\sim 24 \mathrm{~km})$. This height is chosen so as to be roughly consistent with estimates of the height of $\mathrm{SO}_{2}$ injection by the Pinatubo eruption (Read et al., 1993; Guo, 2004b). The model then simulates the full lifecycle of the volcanic aerosols, including oxidation of $\mathrm{SO}_{2}$ to $\mathrm{H}_{2} \mathrm{SO}_{4}$; aerosol formation and growth via nucleation, condensation, accumulation and coagulation; vertical redistribution via sedimentation; and finally the removal processes wet and dry deposition. Previous studies of very large volcanic eruptions with this model set-up (Timmreck et al., 2009, 2010) have shown that explicitly simulating such aerosol processes, and hence a time-evolving aerosol size distribution, leads to a shorter lifetime of sulfate aerosols and a reduced radiative impact compared to other model studies (e.g., Robock et al., 2009; Harris and Highwood, 2011). The full coupling of the HAM module with MAECHAM5 allows for feedbacks, whereby the absorption of outgoing longwave radiation by aerosols, and the associated local heating of the atmosphere, leads to anomalous atmospheric dynamics. Through such feedbacks, the transport of volcanic aerosols can be signif- icantly different than that of a passive tracer (e.g., Young et al., 1994; Timmreck et al., 1999).

\subsection{Model experiments}

We focus here on comparing results from simulations of eruptions of two magnitudes. The magnitude of our larger $\mathrm{SO}_{2}$ injection $(700 \mathrm{Tg})$ is derived from the erupted masses (Kutterolf et al., 2008a,b) and petrological-methodderived $\mathrm{SO}_{2}$ emission estimates (Metzner et al. submitted manuscript) of the "Los Chocoyos tephra" from the $84 \mathrm{ka}$ B.P. eruption at the present-day site of the Atitlan caldera in Guatemala (Rose et al., 1987). Simulations of the Los Chocoyos eruption were performed by injecting $700 \mathrm{Tg}$ of $\mathrm{SO}_{2}$ in the model gridbox closest to $14.6^{\circ} \mathrm{N}, 91.2^{\circ} \mathrm{W}$. We also perform simulations of a hypothetical eruption at the same location with an $\mathrm{SO}_{2}$ injection based on estimates of the $1991 \mathrm{Mt}$. Pinatubo eruption. The latitude of the simulated eruptions is also consistent with the peak of the latitudinal distribution of active volcanoes (Schmincke, 2004). For both eruption magnitudes, we perform simulations with eruptions on the first day of January, April, July and October. Each simulation was run for four years after the eruption. This time period contains the vast majority of the radiative forcing impact of the volcanic aerosols: in the model simulations, stratospheric aerosol loading is found to have decreased to less than $2 \%$ of maximum loading after $4 \mathrm{yr}$ for both eruption magnitudes, which is also consistent with an exponential decay with a 12 month e-folding timescale. In the following, we refer to the two sets of eruption simulations for different eruption seasons as the E700 and E17 experiments, for the 700 and $17 \mathrm{Tg} \mathrm{SO}$ injections, respectively. For each season of eruption, we perform multiple model integrations ( $n=6$ for E700, $n=12$ for E17), where for each integration, the eruption branches from a different year of a $20 \mathrm{yr}$ control run. More ensemble members were performed for the smaller eruption magnitude in order to improve the statistical significance of the smaller ensemble mean anomalies. All results shown are full ensemble means for each magnitude and eruption month. Anomalies are calculated as the difference between experiment runs and the $20 \mathrm{yr}$ control run. All simulations have been performed under present day conditions.

Lastly, in order to better compare with observations of the Pinatubo aerosol evolution, and assess the importance of eruption longitude, we have performed simulations with eruptions on 15 June, at the approximate locations of the Los Chocoyos and Pinatubo eruptions. These results are used only in Sect. 3.

\section{Model validation: Pinatubo comparisons}

Results of a prior MAECHAM5-HAM simulation of the 15 June 1991 Pinatubo eruption were compared to observations by Niemeier et al. (2009). They found that simulated 

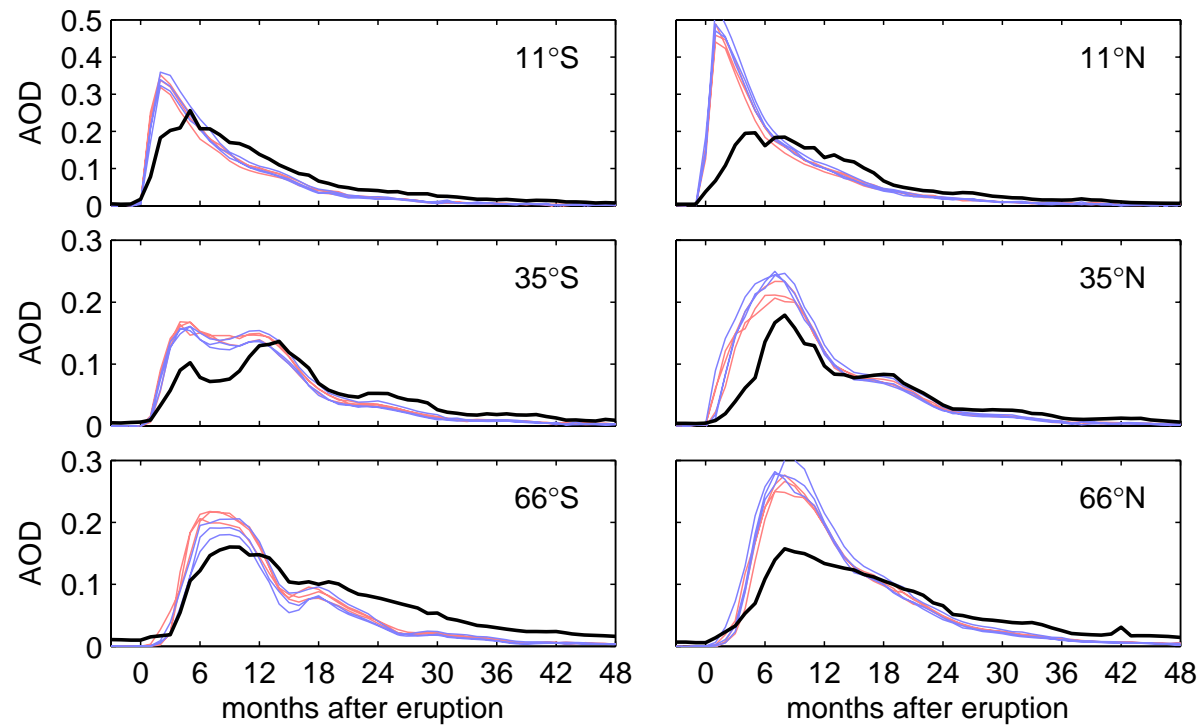

Fig. 1. Monthly-mean, zonal-mean $0.55 \mu \mathrm{m}$ AOD at labelled latitudes, from Pinatubo eruption period observations of the updated Sato et al. (1993) timeseries (black) and MAECHAM5-HAM Pinatubo-magnitude eruption simulations with eruptions at $15^{\circ} \mathrm{N}, 91^{\circ} \mathrm{W}$ (red) and $15^{\circ} \mathrm{N}$, $120^{\circ} \mathrm{E}$ (blue).

zonal mean, monthly mean AOD showed reasonably good agreement with Advanced Very High Resolution Radiometer (AVHRR) and Stratospheric Aerosol and Gas Experiment (SAGE) II satellite observations with respect to the timing and location of peak values, even though the simulations are performed in climatological mode. Quantitatively, peak AOD values from the model were $10-20 \%$ greater than peak values observed by AVHRR, and greater by an even larger factor than SAGE II observations, although SAGE II measurements are highly uncertain in the months immediately after the Pinatubo eruption due to saturation effects (Russell et al., 1996).

Here we compare observations of the impacts of the Pinatubo eruption with new MAECHAM5-HAM simulations of Pinatubo-magnitude eruptions at two different longitudes, in order to test whether the longitude of the eruption site plays any role in the volcanic impacts. The model latitude of the eruption in the two experiments $\left(15.3^{\circ} \mathrm{N}\right)$ is the closest model latitude to that of both the Pinatubo $\left(15.1^{\circ} \mathrm{N}\right)$ and the Los Chocoyos $\left(14.6^{\circ} \mathrm{N}\right)$ eruption sites. The two longitudes used correspond to the closest model longitudes to those of the Pinatubo (120.3 $\left.{ }^{\circ} \mathrm{E}\right)$, and Los Chocoyos $\left(91.2^{\circ} \mathrm{W}\right)$ eruptions.

Figure 1 shows zonal mean mid-visible $(0.55 \mu \mathrm{m})$ volcanic AOD at labeled latitude bands from an ensemble of Pinatubomagnitude eruption simulations compared to the those from the Sato et al. (1993, with update retreived from data.giss. nasa.gov/modelforce/strataer) AOD timeseries, based in this time period on measurements from the SAGE II satellite instrument. As in Niemeier et al. (2009), the model AOD is notably larger than the observations in the months immediately following the eruption. AVHRR retrievals (not shown here) have an AOD maximum in the tropics of approximately 0.3 , in closer agreement with the AOD of the model. In the tropics, the model AOD falls below the Sato et al. (1993) AOD after approximately 6 months, and the decay of AOD in the tropics is faster in the model than observed. In the extratropics, while the magnitude of the model peak AOD is again larger than that of the observations, the timing of the peaks is quite consistent with the observations. The seasonality of the AOD evolution is also quite consistent between model and observations: note for example the double-peak at $35^{\circ} \mathrm{S}$ at approximately 5 and 12 months after the eruption, and the periodic flattening of the AOD decay at $35^{\circ} \mathrm{N}$ between 12 and 18 months, and 24 and 30 months. The decay in AOD at the high latitudes is faster in the model than in observations, especially in the SH. Niemeier et al. (2009) found the model aerosol effective radius to be consistent with midlatitude lidar measurements, albeit at the upper limit of those measurements, and suggested a slight high-bias in the model effective radius might lead to larger sedimentation rates, explaining the faster decay of AOD in the model.

Figure 2 shows top-of-atmosphere (TOA) SW radiative flux anomalies from the model simulations compared to observations by the Earth Radiation Budget Experiment (ERBE) (Barkstrom, 1984; Barkstrom and Smith, 1986). We have used Edition 3 Rev 1 data set from the Earth Radiation Budget Satellite (ERBS) Nonscanner Wide Field of View, which have been corrected for a change in satellite altitude and instrument drift during the measurement period, and agree well with other satellite-based earth radiation budget records (Wong et al., 2006). Since monthly means have been found to create a spurious semi-annual cycle in the data, 36day averages are used (Wielicki et al., 2002) in the tropical 

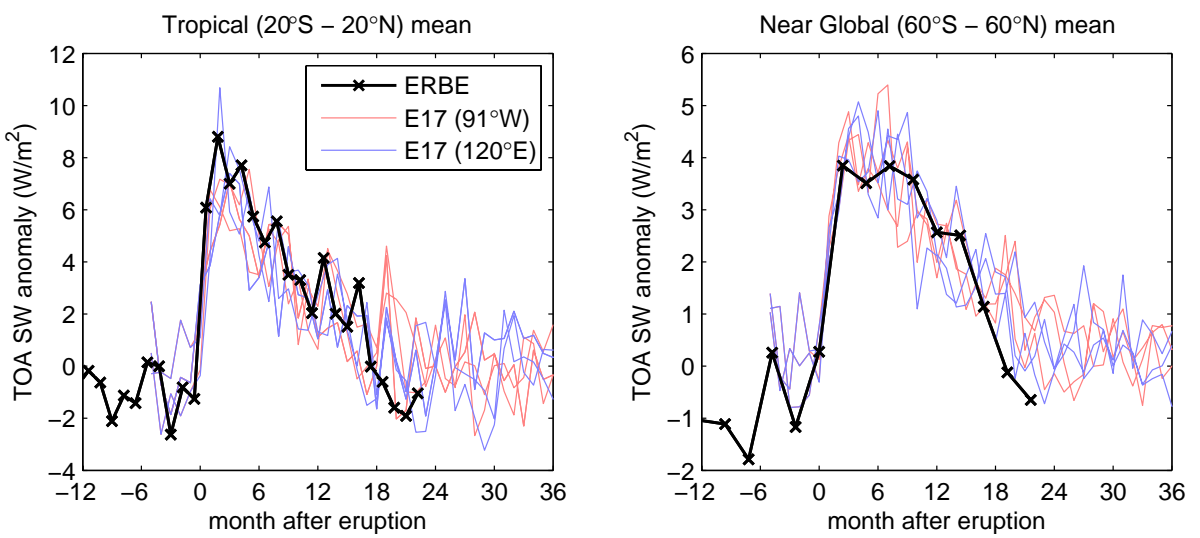

Fig. 2. Tropical $\left(20^{\circ} \mathrm{S}-20^{\circ} \mathrm{N}\right)$ and near-global $\left(60^{\circ} \mathrm{S}-60^{\circ} \mathrm{N}\right)$ reflected shortwave flux anomalies at the top of the atmosphere from Pinatubo eruption period ERBE observations (black) and MAECHAM5-HAM Pinatubo-magnitude eruption simulations with eruptions at $15^{\circ} \mathrm{N}$, $91^{\circ} \mathrm{W}$ (red) and $15^{\circ} \mathrm{N}, 120^{\circ} \mathrm{E}$ (blue). Model anomalies calculated with respect to a 20 -yr control simulation, ERBE anomalies calculated with respect to the 1985-1989 mean.

data set, and 72-day means in the near-global data set. ERBE TOA SW anomalies are calculated with respect to the 19851989 mean, while model anomalies are calculated with respect to a 20 year control simulation. MAECHAM5-HAM simulated TOA SW flux anomalies show excellent agreement with the ERBE observations, in both tropical and near-global mean.

The fact that model TOA SW flux anomalies agree well with ERBE suggests the discrepancy between model and observed AOD immediately following the eruption may be more a function of underestimated observations rather than an overestimate by the model. After the initial post-eruption period, discrepancies between model and observed AODs suggest the model overestimates the transport of aerosol to high latitudes, and has a faster removal rate. Nonetheless, the qualitative features of aerosol transport in the model agree reasonably well with observations, including the timing of peak AOD levels, and seasonal variations in AOD decay rate.

Simulations of Pinatubo-strength eruptions at two different longitudes showed no systematic bias in AOD evolution or radiative impact in our MAECHAM5-HAM runs. This result increases confidence that the results of the next section can be regarded as applicable to eruptions at a particular tropical latitude at the locations of both the Mt. Pinatubo and Los Chocoyos eruptions, i.e., from both the Eastern and Western arm of the Pacific "Ring of Fire".

\section{Sensitivity experiments}

Here we investigate the aerosol transport and short-wave radiative impacts of simulated tropical eruptions, and the sensitivity of these impacts to eruption season. Since the primary climatic impact of volcanic aerosols is the reflection of solar SW radiation, which decreases the SW radiative flux at the Earth's surface, and hence the energy input to the Earth system, we focus here on anomalies in SW surface fluxes with respect to climatological values from a control run. In addition to surface flux anomalies, we have also examined top-of-atmosphere SW flux anomalies, but since the results are very similar, only the results of our analysis of surface fields will be shown here. However, as will be shown, sensitivity to eruption season is different for clear-sky and all-sky $\mathrm{SW}$, therefore both fields will be considered. In addition, we also consider the mid-visible $(0.55 \mu \mathrm{m})$ volcanic AOD, also calculated as the anomaly in AOD between the volcanically perturbed simulations and a control run. Each of these fields will be considered in terms of zonal and global means. Two eruption magnitudes are investigated, and are discussed separately in the following two subsections.

\subsection{E17: Pinatubo-magnitude experiment}

Through inspection of the zonal mean AOD evolution for the E17 experiment (Fig. 3a), it is clear the season of eruption plays a significant role in the timing and strength of volcanic aerosol transport out of the tropics into the extratropics. The qualitative features of the AOD distributions of Fig. 3a can be explained in terms of the seasonal variation of the BDC, with, for example, stronger aerosol transport to the $\mathrm{NH}$ after eruptions in NH fall (Oct) and winter (Jan) leading to larger AOD values in the $\mathrm{NH}$. The transport of aerosols is not symmetric with respect to hemisphere and season for this eruption magnitude and location, i.e., the transport to the $\mathrm{SH}$ midlatitudes for a $\mathrm{SH}$ winter eruption is much weaker than to the $\mathrm{NH}$ midlatitudes for a $\mathrm{NH}$ winter eruption. This is likely related to the fact that the BDC is stronger in $\mathrm{NH}$ winter than in $\mathrm{SH}$ winter since the distribution of the Earth's land masses leads to stronger planetary waves in the NH. However, the latitude of the eruption in our simulations, on the northern side of the equator, could also play a role in producing the hemispheric bias in AOD distribution. 

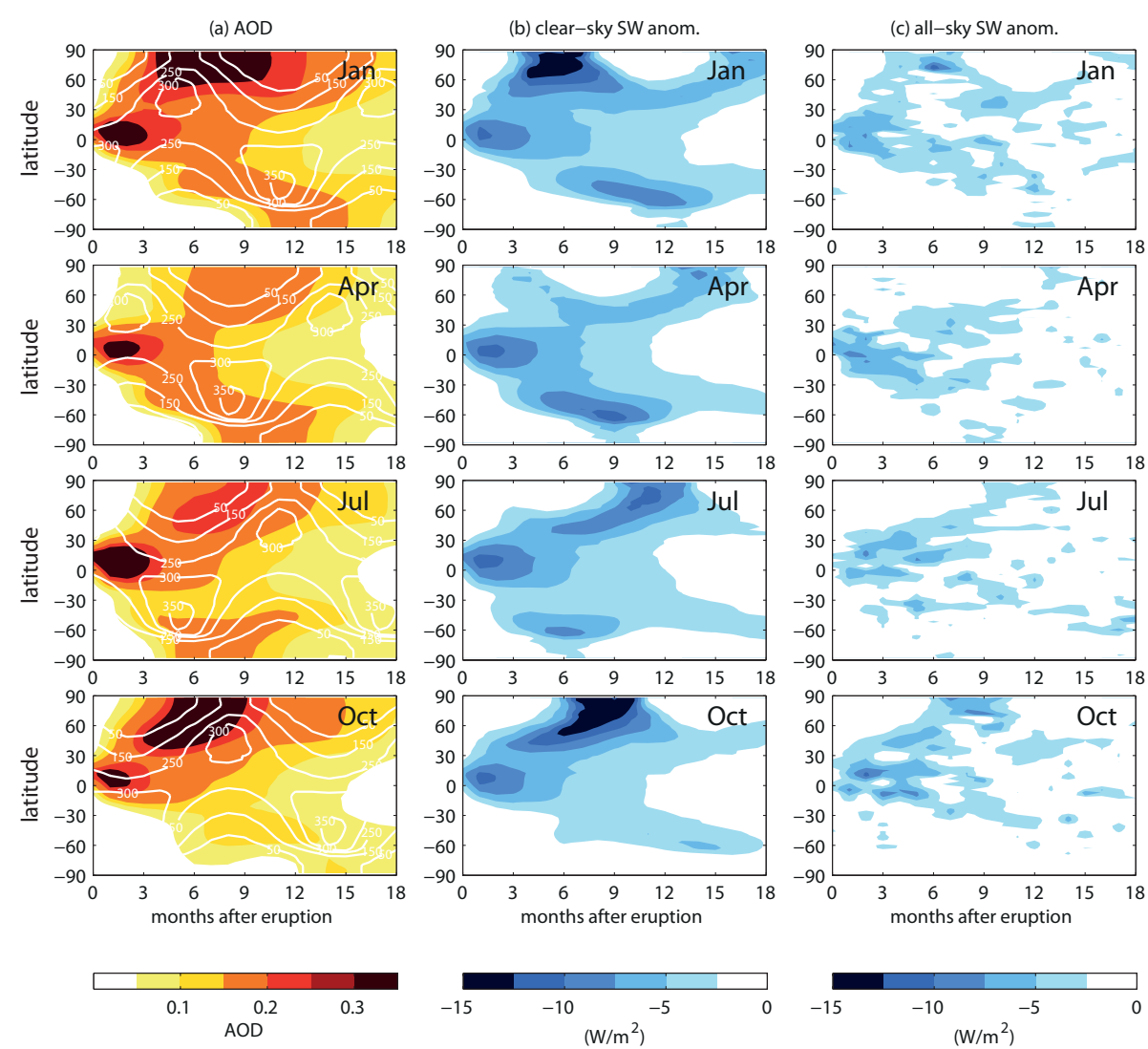

Fig. 3. Zonal mean, monthly mean $0.55 \mu \mathrm{m}$ aerosol optical depth (a), clear-sky surface shortwave radiation anomalies (b) and all-sky surface shortwave anomalies (c) for E17 eruptions in January, April, July and October. White contours in column (a) show climatological surface clear-sky shortwave radiation: visual contrast between color shading and white contours is used to highlight climatological radiative flux at timing of large AOD. All anomalies shown are ensemble mean differences from a control run, and are significant at the $95 \%$ confidence level.

Clear-sky surface SW anomalies are given in Fig. 3b. These absolute anomalies are a function of both the spatiotemporal evolution of the volcanic AOD, and the seasonally varying solar insolation pattern (also shown in Fig. 3a). As a result, clear-sky SW anomalies do not exactly follow the AOD patterns: for example, 6-9 months after an April eruption the AOD pattern is reasonably hemispherically symmetric, while the clear-sky SW anomalies are much stronger in the SH, owing to the fact that this time period coincides with SH summer when the local solar insolation is at a maximum. Note also that the AOD maximum at high NH latitudes for a January eruption coincides exactly with maximum solar insolation, leading to quite strong clear-sky SW anomalies.

All-sky surface shortwave anomalies are shown in Fig. 3c. These anomalies are a function of the clear-sky SW anomalies and the degree of cloudiness in the model. The climatological ratio of all-sky to clear-sky SW from the control run is given in Fig. 4. Maximum cloudiness (hence lowest all-sky to clear-sky ratio) is found in the mid- to high latitudes, which explains the reduction in the relative amplitude of the all-sky SW anomalies in the high latitudes com- pared to in the tropics. Clouds add a large degree of noise to the all-sky SW anomaly field: the standard deviation of the monthly mean, zonal mean all-sky SW radiative flux of the climatology, which quantifies the interannual variability of the field, is shown in Fig. 4. The ensemble mean all-sky SW anomalies shown in Fig. 3c, with maximum magnitudes of $5-10 \mathrm{~W} \mathrm{~m}^{-2}$, are roughly comparable to the standard deviation of all-sky SW in the control run. This means that while the all-sky SW anomalies in Fig. $3 \mathrm{c}$ are significant in the ensemble mean, they are of the same magnitude as the natural interannual variability of the model all-sky SW field.

Quantifying the influence of eruption season on the radiative impact amounts to condensing the information in Fig. 3 into some measure of sensitivity. As a first step, we integrate the anomalies shown in Fig. 3 in time, leading to cumulative anomalies. A cumulative anomaly of SW radiation expresses the change in solar energy arriving at the surface as a consequence of the volcanic eruption. A cumulative anomaly is a robust measure of the impact (compared to, e.g., a time average) as long as one integrates for a few years after the eruption, since volcanic anomalies typically decay exponentially 

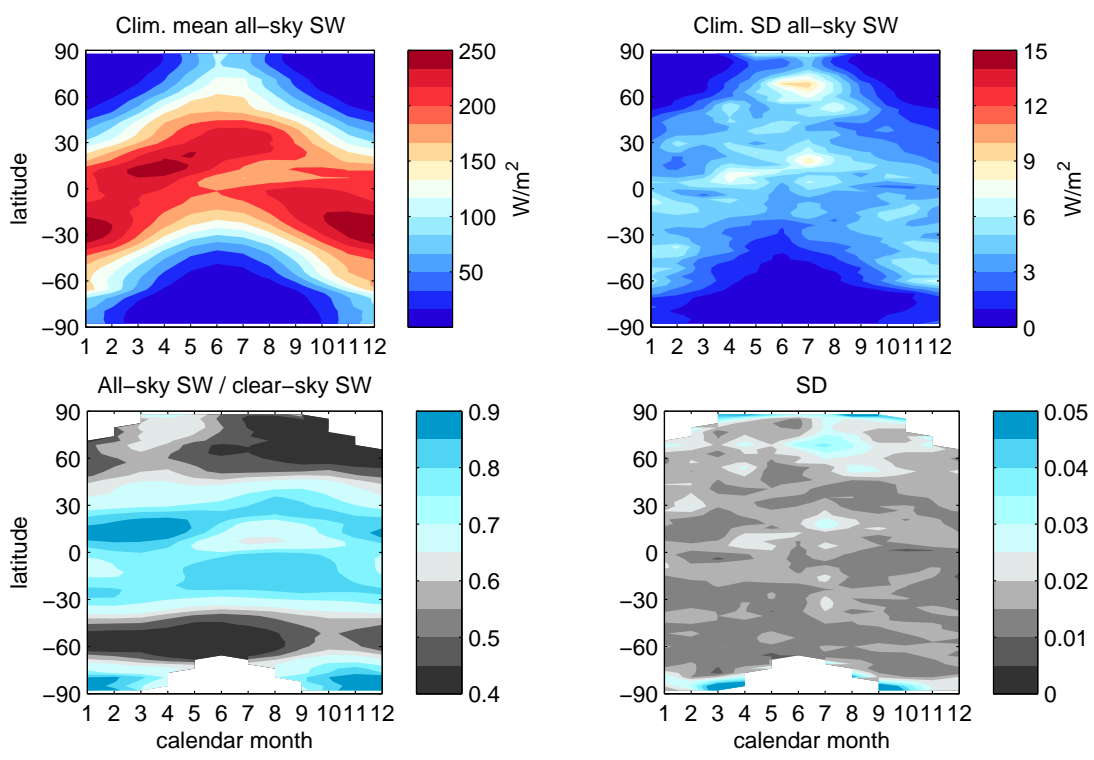

Fig. 4. MAECHAM5-HAM climatological mean, zonal mean values of all-sky SW surface radiation (top) and ratio of all-sky to clear-sky SW surface radiation (bottom) along with the interannual variability of each zonal mean field quantified by the standard deviation (SD).

with a time scale of about one year (Robock, 2000). We calculate cumulative AOD and SW anomalies by summing the respective field over four years, and are presented in units of months (for the unitless AOD) and $\mathrm{W} \mathrm{m}^{-2} \times$ months for SW anomalies. It should be noted that cumulative SW anomalies as calculated here are a measure of energy per unit energy, and can easily be scaled to more conventional units $\left(1 \mathrm{~W} \mathrm{~m}^{-2} \times\right.$ months $\left.=2.6 \times 10^{6} \mathrm{~J} \mathrm{~m}^{-2}\right)$, but are shown here in $\mathrm{W} \mathrm{m}^{-2} \times$ months for easier comparison with the cumulative unit of AOD and the raw anomalies of Fig. 3.

Figure 5 shows cumulative AOD, clear-sky SW and all-sky SW anomalies in terms of zonal and global means. Cumulative fields for eruptions in different seasons are designated by colors. The influence of season on the impact of volcanic eruptions can be quantified by comparing the magnitude of the impact for the eruption month in which the impact is greatest, to the magnitude of impact for the eruption month in which the impact is smallest. Differences between maximum and minimum response are shown by black lines for each latitude. Gray shading indicates the $95 \%$ confidence interval of the max-to-min differences, as calculated using the student's t-test.

Examining first the cumulative AOD, we see the largest sensitivity to eruption season in the $\mathrm{NH}$ mid- to highlatitudes. The January eruption simulations lead to the highest AOD values from $30^{\circ} \mathrm{S}$ to $90^{\circ} \mathrm{N}$, and south of $30^{\circ} \mathrm{S}$ the AOD for January eruption is only slightly lower than that for an April eruption. In the global mean, a January eruption leads to a significantly larger AOD than for the other months. We explore reasons for the larger cumulative AOD seen for a January eruption with the aid of Fig. 6. The AOD for a January eruption is larger than for other eruption months from approximately four months after the eruption onward (Fig. 6a). While the global sulfate mass burden (Fig. 6b) for all eruption months are comparable for the first 6-8 months, the aerosol effective radius (Fig. 6c) is notably smaller for a January eruption. Smaller aerosols scatter SW radiation more efficiently, and also have a smaller sedimentation rate, which increases their stratospheric lifetime. Through these related mechanisms, a smaller aerosol effective radius can explain the larger January eruption AOD in the E17 experiment. The smaller effective radius for the January eruption is itself likely related to the vertical distribution of sulfate for a January eruption. Sulfate burdens for a January eruption are notably shifted to higher altitudes than for other eruption months. Figure $6 \mathrm{~d}$ shows, for example, the sulfate mass fraction timeseries at $10 \mathrm{hPa}$, a few $\mathrm{km}$ above the $\mathrm{SO}_{2}$ injection height, for which the sulfate abundance following the January eruption is larger than for all other eruption months. It has been shown (Niemeier et al., 2010) that the stratospheric injection height of $\mathrm{SO}_{2}$ has an appreciable effect on aerosol size, with higher injection heights leading to smaller particles. It appears that in the experiments described here, the season of eruption has an influence on aerosol size through the seasonal cycle of tropical upwelling, which is driven by extratropical wave breaking and has been shown in reanalysis data to have a strong maximum in NH winter (e.g., Randel et al., 2002; Krüger et al., 2009). GCMs typically reproduce this $\mathrm{NH}$ winter maximum in tropical upwelling, although the season of minimum upwelling is model dependent (SPARC CCMVal, 2010). As a result of a $\mathrm{NH}$ winter maximum in tropical upwelling, stratospheric $\mathrm{SO}_{2}$ injections during $\mathrm{NH}$ winter should lead to aerosol formation at higher altitudes on average, which in turn leads to a smaller overall effective 
(a) cumulative AOD, zonal mean

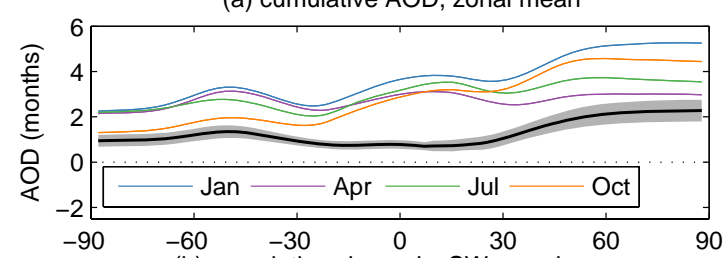

(b) cumulative clear-sky SW, zonal mean

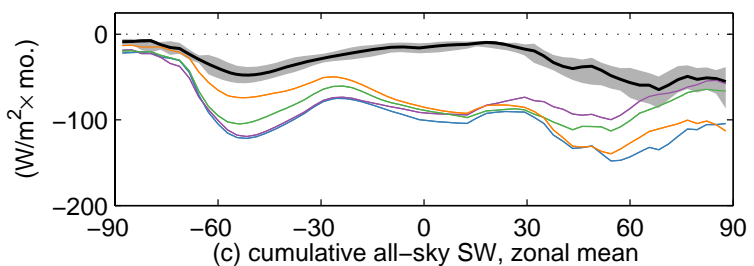

(c) cumulative all-sky SW, zonal mean

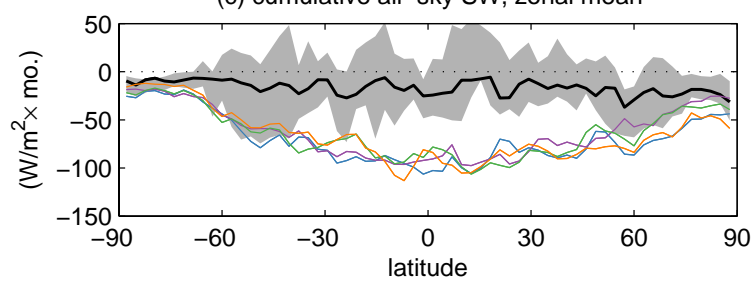

(d) global mean

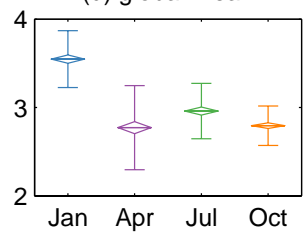

(e) global mean

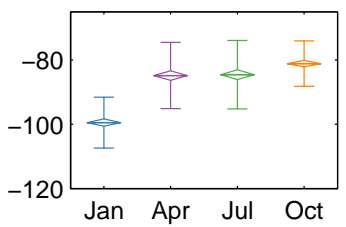

(f) global mean

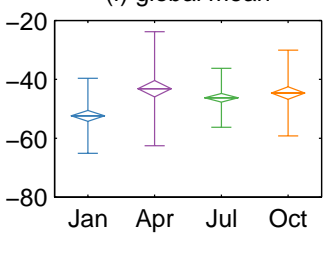

Fig. 5. Zonal mean (left) and global mean (right), four-year-cumulative post-eruption anomalies in AOD (top), clear-sky surface shortwave radiation anomalies (middle) and all-sky surface shortwave anomalies (bottom) for the E17 experiment. Eruption seasons indicated by colors. Black lines in zonal mean plots show mean difference between maximum and minimum response at each latitude, with shading indicating $95 \%$ confidence interval of difference based on the student's t-test. In global mean plots, horizontal lines within diamonds indicates ensemble mean, vertical range of diamonds indicates standard error of mean, and vertical error bars indicate $2 \sigma$ ensemble variability.

radius of the aerosols. Thus, because of the seasonality of stratospheric dynamics, the season of eruption may influence not only the horizontal transport of volcanic aerosols, but also the microphysical formation, growth, and hence size distribution of the aerosols, and the cumulative global mean AOD.

Cumulative clear-sky SW anomalies (Fig. 5b) show largest sensitivity in $\mathrm{NH}$ extratropics and $\mathrm{SH}$ midlatitudes. Like the AOD, largest clear-sky SW anomalies in the NH are produced by a January eruption. Kravitz and Robock (2011) found that for high latitude eruptions, maximum SW anomalies occured for summer eruptions: their results are consitent with ours when one considers that the peak in high latitude AOD in our simulations occurs roughly 6 months after the tropical eruptions (see Fig. 3). The global mean clear-sky SW anomaly for a January eruption is significantly larger than those for the other eruption months.

In contrast to the AOD and clear-sky SW anomalies, cumulative all-sky SW anomalies for the different seasons of eruption are basically indistinguishable. Differences between the eruption seasons are insignificant at most latitudes.

In order to compare the degree of sensitivity to eruption season of the fields in Fig. 5, a percent sensitivity is shown in Fig. 7, where percent sensitivity refers to the max-minusmin difference divided by the minimum response. A $100 \%$ sensitivity then implies that the maximum response is twice that of the minimum response. Thick lines in Fig. 7 refer to where the sensitivity is significant at the $95 \%$ level, i.e., where the gray confidence intervals of Fig. 5 do not include zero.

Percent sensitivity for AOD is minimum in the tropics, and increases towards the poles, reaching maximums of $\sim 75 \%$. Clear-sky SW percent sensitivity is smaller than that of the AOD in the tropics, but somewhat larger in the NH high latitudes, owing to the amplifying effect of the strong seasonal cycle in solar insolation at the high latitudes. All-sky SW sensitivity is notably weaker than the clear-sky SW and AOD sensitivity, and is only significant at a few latitudes in the high latitudes in both hemispheres.

The sensitivity of the global mean AOD and clear-sky SW anomalies are on the order of 20-30\%, and are both significantly greater than zero. On the other hand, the global mean all-sky SW anomalies are greatly reduced compared to the AOD and clear-sky sensitivity, and is not significantly greater than zero. This reduction in sensitivity suggests the presence of some mechanism that reduces the sensitivity of allsky SW anomalies compared to clear-sky SW anomalies and AOD. It has been noted (e.g., Bender et al., 2010) that climate models often produce a decrease in cloud fraction as a result of volcanic forcing. Post-eruption decreases in clouds can be understood to be a result of decreases in evaporation following decreases in SW radiation at the surface (e.g., Soden et al., 2002), although other processes that might affect cloud cover in reality, such as changes in cloud condensation nuclei 
(a) AOD

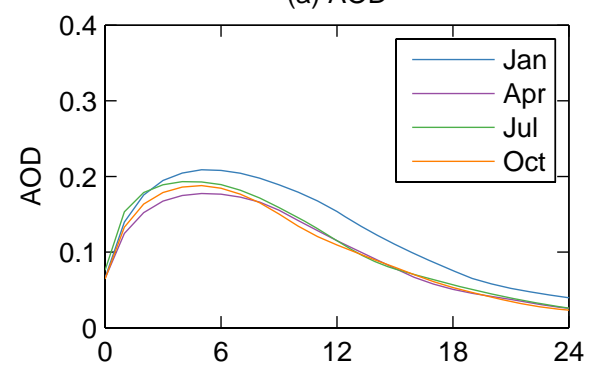

(c) sulfate Reff at $100 \mathrm{hPa}$

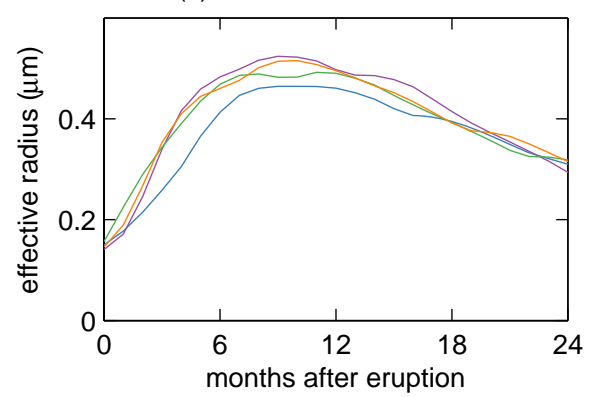

(b) sulfate burden

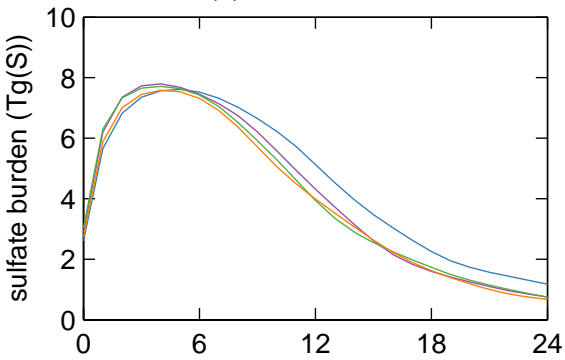

(d) sulfur mass fraction at $10 \mathrm{hPa}$

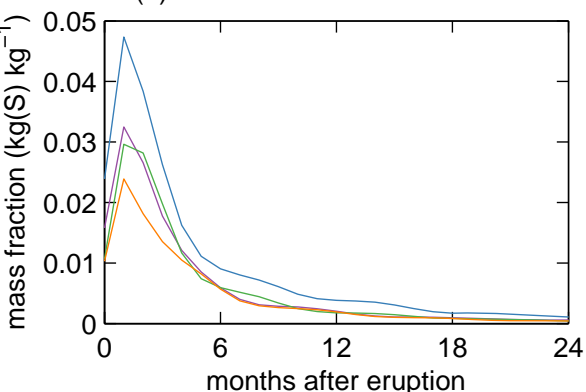

Fig. 6. Timeseries of (a) global mean AOD, (b) global sulfate mass burden, (c) global mean sulfate aerosol effective radius at $100 \mathrm{hPa}$, and (d) global mean sulfate mass fraction at $10 \mathrm{hPa}$.

(a) cumulative sensitivity, zonal mean

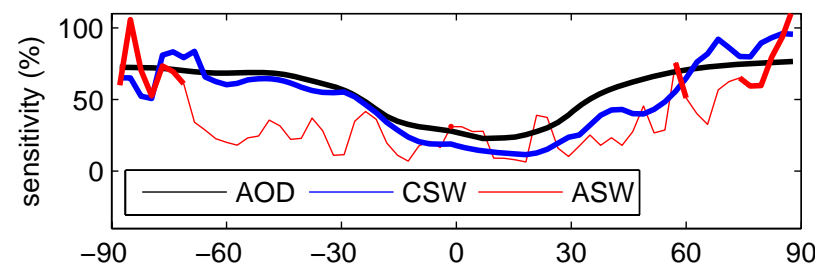

(b) global mean

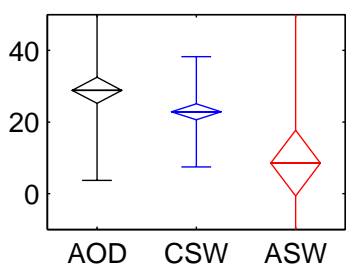

Fig. 7. Percent sensitivity to eruption season for cumulative anomalies of AOD (black), clear-sky surface shortwave radiation (blue) and all-sky surface shortwave radiation (red), calculated as difference between maximum and minimum response (black lines in Fig. 5) divided by minimum response. Zonal mean quantities plotted versus latitude to left (a), global mean quantities plotted in contracted y-scale to right (b). Thick lines in panel a show where response is significant at the $95 \%$ level. In panel (b), horizontal lines within diamonds indicates ensemble mean, vertical range of diamonds indicates standard error of mean, and vertical error bars indicate $2 \sigma$ ensemble variability.

are typically not included in climate models. In any case, such a negative feedback mechanism - wherein decreases in surface SW brought about by reflection of SW by volcanic aerosols are partially compensated by increases in surface SW brought about by decreases in cloud cover - could conceivably lead to a reduction in the sensitivity of all-sky SW radiative flux to eruption season. A detailed analysis of cloud feedbacks is beyond the scope of this work.

\subsection{E700: near-super eruption experiment}

Similar to the results for E17, for E700 (Fig. 8a) there are larger AOD values in the hemispheres for which the eruption occurs in winter and fall, following the expected seasonal cycle of the BDC. For E700, the hemispheric asymmetry in
AOD is relatively symmetric with respect to season, in the sense that the aerosol burden for a July eruption is roughly the mirror image of that for the January eruption.

The most striking difference in the large-scale spatiotemporal morphology of the AOD between the two eruption magnitudes is the appearance of strong gradients in AOD at $\sim 60^{\circ} \mathrm{N}$ and $\sim 60^{\circ} \mathrm{S}$ in the E700 simulations. It was shown that absorption of infrared radiation by volcanic aerosols after the $1991 \mathrm{Mt}$. Pinatubo eruption changed the meridional temperature gradient in the stratosphere (Labitzke and McCormick, 1992), which, through the thermal wind balance, led to westerly anomalies in zonal mean zonal wind (e.g., Kodera, 1994; Perlwitz and Graf, 1995; Kirchner et al., 1999; Kodera and Kuroda, 2000a,b; Shindell et al., 2001). In the E700 simulations, aerosol effective radius grows within three 

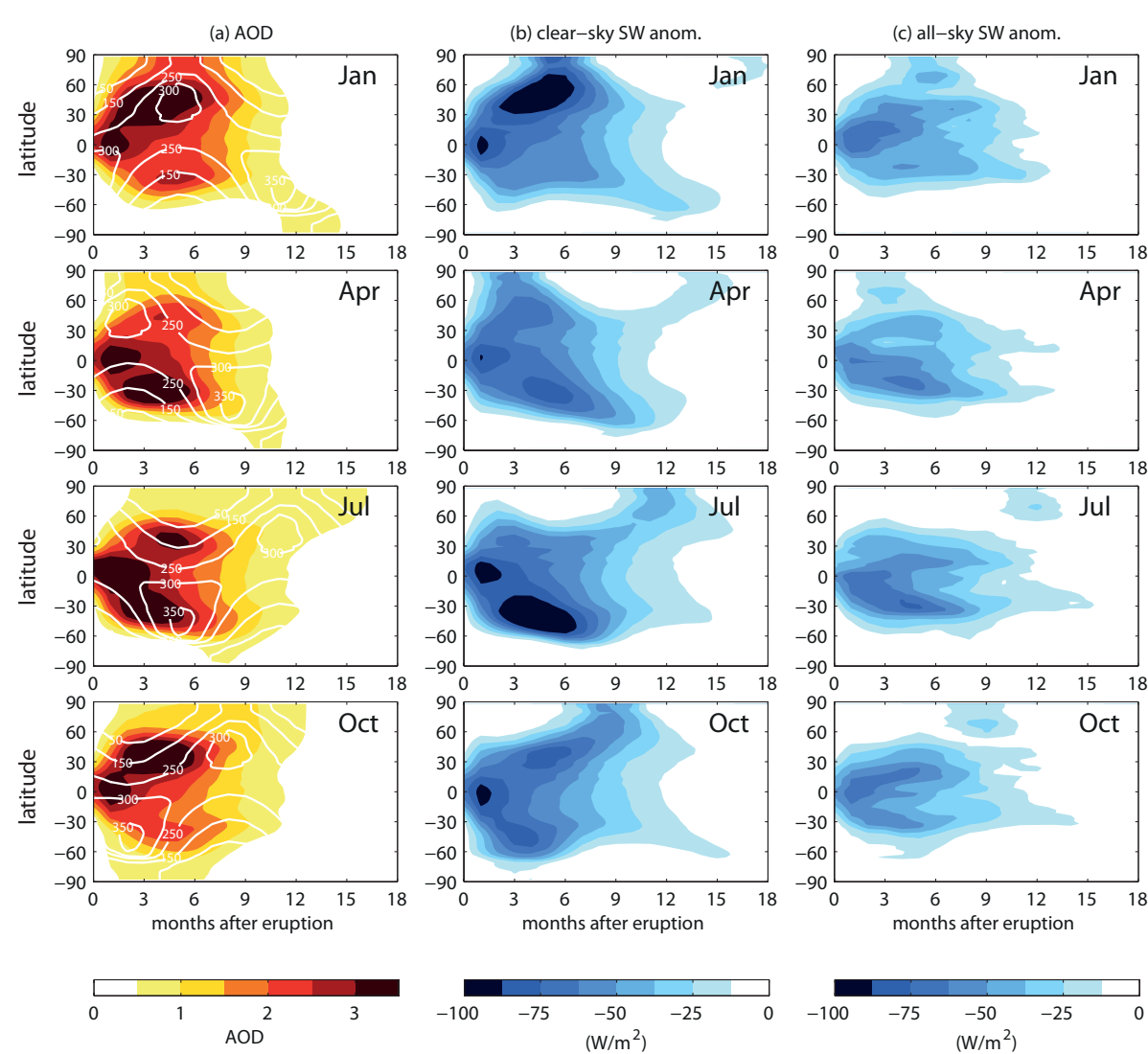

Fig. 8. As Fig. 3, for the E700 experiment.

months to values greater than $1 \mu \mathrm{m}$ throughout the stratosphere between approximately $30^{\circ} \mathrm{S}$ and $30^{\circ} \mathrm{N}$, and absorption of infrared radiation by these large and abundant aerosols leads to temperature anomalies of over $30 \mathrm{~K}$ (not shown here), and significant anomalies in zonal wind. Figure 9 shows the time evolution of the volcanically induced anomalous zonal wind at $50 \mathrm{hPa}$ at $60^{\circ} \mathrm{N}$ and $60^{\circ} \mathrm{S}$, for both E17 and E700 experiments. The zonal wind anomalies for E700 are strong enough that they produce winterlike polar-vortices simultaneously in both hemispheres, lasting for more than a year after the eruption. Polar vortices act as barriers to meridional transport (Schoeberl and Hartmann, 1991), and we hypothesize that the blocking of poleward aerosol transport at the induced polar vortex enhances the local meridional gradient in aerosol burden, in turn enhancing the temperature anomaly gradient and the resulting zonal wind anomalies. This constitutes a positive feedback mechanism which can help explain the persistence of the induced polar vortices. In both hemispheres, for all seasons of eruption, wind anomalies following the E17 eruptions are insignificant compared to the natural variability, while for E700, ensemble mean zonal wind anomalies are significantly larger than the $95 \%$ natural variability bounds for 12 18 months after the eruption. In the $\mathrm{SH}$, the anomalies are almost twice as strong, with peak anomalies reaching almost
$50 \mathrm{~m} \mathrm{~s}^{-1}$ at this latitude and height. As in the NH, the SH anomalies are significant for around 12 to 18 months after the eruption, but in contrast to the $\mathrm{NH}$, the anomalies vary somewhat with local season, with peaks occurring in SH fall (characteristic of a early forming winter vortex) and in $\mathrm{SH}$ spring (characteristic of a long-lasting winter vortex).

Clear-sky SW anomalies, shown in Fig. 8, are a function of both the AOD and the seasonal and latitudinal variations in solar insolation. Latitude-time AOD evolution is roughly similar for the January and October eruptions, with stronger AOD in the NH midlatitudes than in the SH midlatitudes. However, the clear-sky SW anomalies are relatively equal between hemispheres for the October eruption, but much more asymmetric for the January eruption, with larger anomalies in the NH. This is a result of the NH peak in AOD coinciding with the NH peak in solar insolation, while the October eruption $\mathrm{NH}$ peak in AOD occurs roughly in the midpoint of the midlatitude solar insolation cycle.

As was the case for E17, clouds greatly reduce the volcanic impact on all-sky SW anomalies in the mid- to high-latitude regions. As a result, much of the sensitivity to eruption season displayed by the clear-sky fields is greatly reduced in the all-sky SW field: for example the all-sky SW anomalies for January and October are much more similar than the clearsky SW anomalies for the same months. 

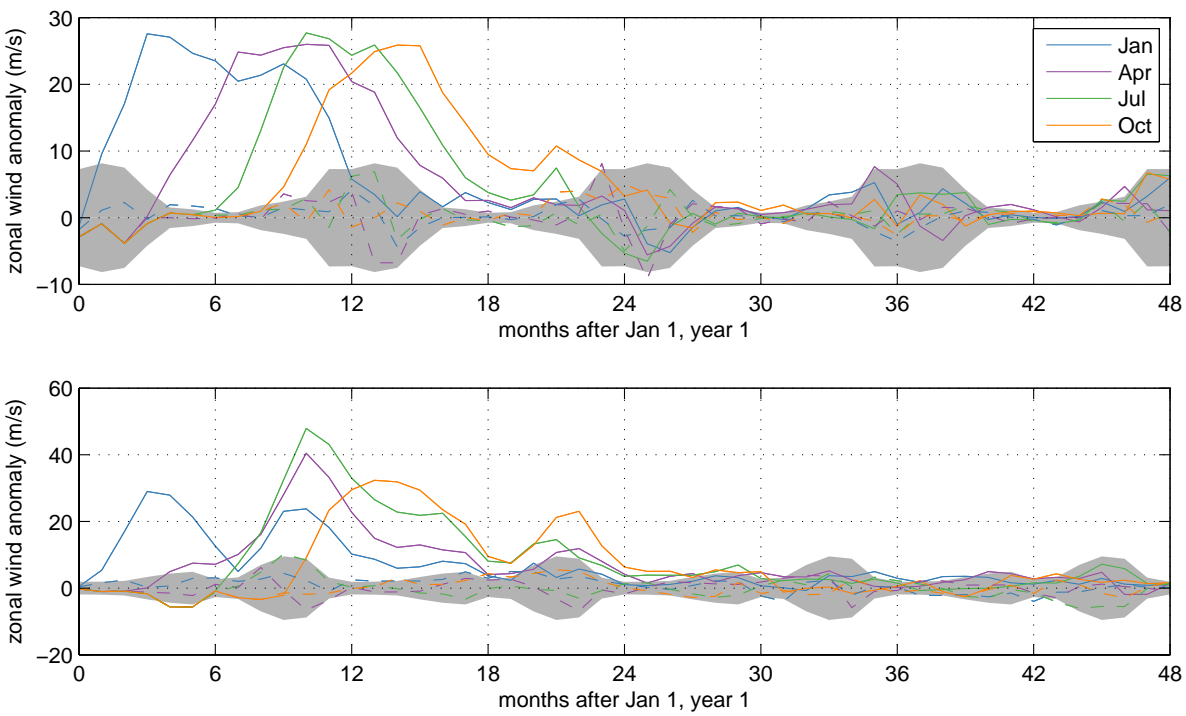

Fig. 9. Zonal mean zonal wind anomalies at $50 \mathrm{hPa}$ and $60^{\circ} \mathrm{N}$ (top) and $60^{\circ} \mathrm{S}$ (bottom) for E700 (solid lines) and E17 (dashed lines) eruption simulations. Anomalies outside the gray shading are significant at the $95 \%$ confidence level based on the variability of a control run. Note different scales for the $\mathrm{NH}$ and $\mathrm{SH}$ plots.

(a) cumulative AOD, zonal mean

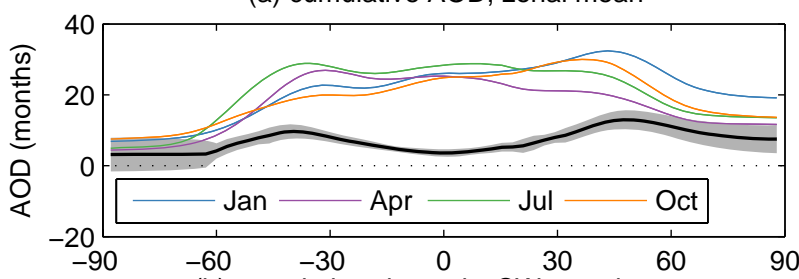

(b) cumulative clear-sky SW, zonal mean

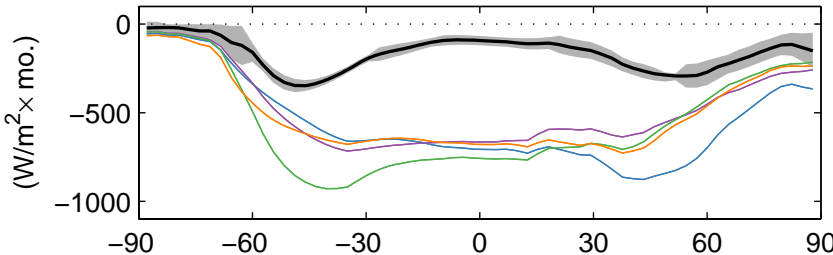

(c) cumulative all-sky SW, zonal mean

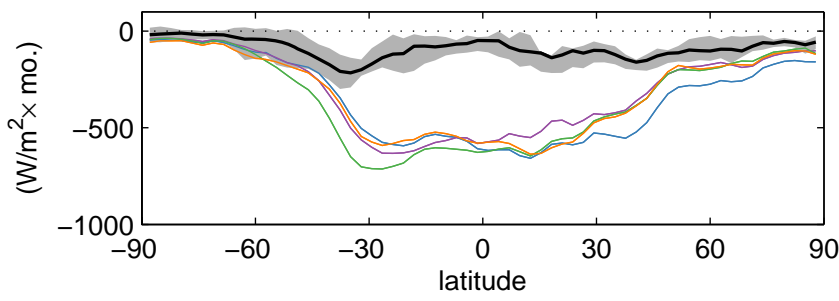

(d) global mean

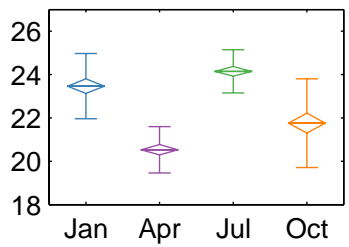

(e) global mean

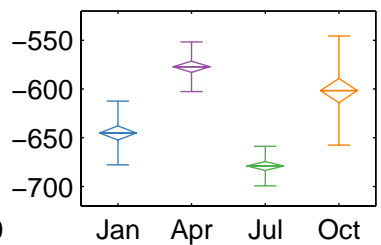

(f) global mean

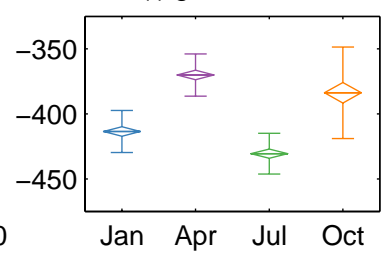

Fig. 10. As Fig. 5, for the E700 experiment. Note different y-axes.

Figure 10 shows cumulative AOD and SW anomalies for the E700 experiment. In terms of zonal mean AOD, maximum AOD sensitivity to eruption season is found in the mid-latitudes, similar to the E17 results. In terms of global mean AOD, for this eruption magnitude, both January and July eruptions lead to larger global mean AODs than April and October eruptions. Examination of effective radius and aerosol burden at $10 \mathrm{hPa}$ (not shown) reveals that, as was the case for E17, the larger global mean AODs are linked to higher peak altitude of the aerosol vertical profile and smaller effective radius. However, the seasonal cycle in tropical upwelling used to explain the January maximum AOD for E17 
(a) cumulative sensitivity, zonal mean

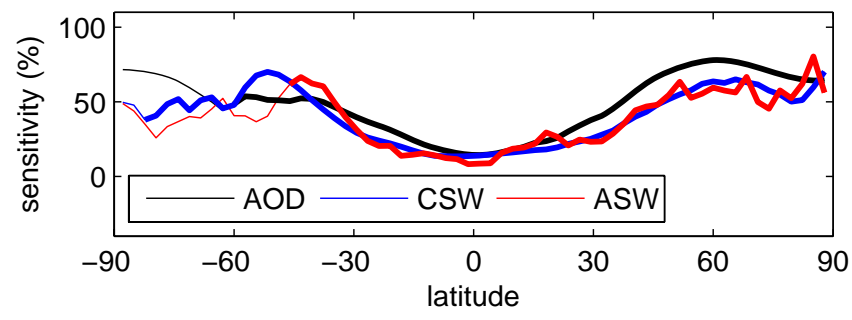

(b) global mean

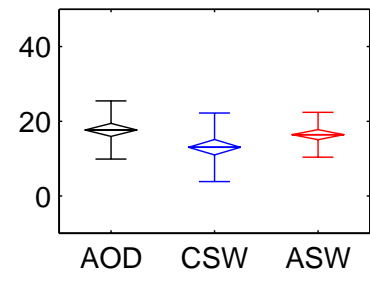

Fig. 11. As Fig. 7, for the E700 experiment. Note different y-axes.

cannot give rise to both January and July maximum seen here for E700. It should be kept in mind though that the aerosol heating for E700 significantly changes stratospheric dynamics, such as the zonal winds (as shown above) and the tropical upwelling. Therefore the seasonal dependence of global mean AOD evolution appears to depend not just on the background seasonal cycle of tropical upwelling, but also on the degree of perturbation to stratospheric dynamics by aerosol heating. Future work will be required to fully understand the coupling between tropical upwelling, aerosol microphysical formation and growth and aerosol heating, and the effects of such couplings on the radiative impact of stratospheric sulfur injections.

Clear-sky SW anomalies roughly follow the AOD patterns, and show maximum sensitivity to eruption season at $\sim 50^{\circ}$ in both hemispheres. However, due to clouds, the absolute reduction in all-sky $\mathrm{SW}$ anomalies is greatly suppressed in the $40-60^{\circ}$ regions. In contrast to the E17 experiment, the absolute sensitivity to eruption season is significantly greater than zero everywhere except the $\mathrm{SH}$ high latitudes, although it is relatively weak in the tropics and NH high latitudes.

Percent sensitivities to eruption season for E700 are shown in Fig. 11. As for E17, E700 AOD sensitivity is minimum in the tropics, and increases with latitude. However, blocking of poleward transport of aerosols by the induced polar vortices leads to a weakened sensitivity at polar latitudes, resulting in maximum AOD sensitivity for E700 around 50-65 in each hemisphere. The sensitivity of both clear-sky and all-sky SW anomalies is generally less than that of AOD, except for approximately $40-60^{\circ} \mathrm{S}$.

In the E700 eruption experiment, zonal mean and global mean AOD show smaller percent sensitivity to eruption season than was the case for the E17 experiment, with global mean sensitivity of $\sim 18 \%$ compared to $25 \%$ for E17. Similarly, the clear-sky SW anomaly percent sensitivity for E700 is less than that of E17. The smaller relative sensitivity to eruption season for the E700 experiment compared to E17 as calculated here is due to a combination of at least two factors. Firstly, the aerosol distribution and AODs resulting from the E700 eruptions are more hemispherically symmetric than for E17. As the aerosol geographic distribution becomes more uniform with increasing eruption magnitude, the percent sensitivity to eruption season is seen to decrease. Secondly, it should be pointed out that our estimates of sensitivity are lower limits, since we test only four eruption dates, and thus a maximum-to-minimum sensitivity calculated using a larger number of eruption dates can only be larger than our estimates. The degree to which this sampling error of our experiment underestimates the true sensitivity is related to the timescale of the impacts. Since the peak in AOD for the E700 simulations is shorter-lived than in the E17 simulations, it is likely that our analysis method underestimates the true sensitivity of the larger eruption more strongly than for the weaker eruption.

Whereas global mean all-sky anomaly sensitivity for E17 was found to be much reduced compared to AOD, and insignificant, the all-sky SW anomaly sensitivity for E700 is comparable to that of the AOD, with magnitude of $\sim 18 \%$, and is significantly greater than zero. In the extratopics of both hemispheres, all-sky SW anomaly sensitivity is often greater than $50 \%$.

\section{Conclusions}

In this study, MAECHAM5-HAM coupled aerosol-GCM simulations have been used to assess the influence of eruption season on the impacts of tropical eruptions. Model simulations of the $1991 \mathrm{Mt}$. Pinatubo eruption show excellent agreement with TOA SW flux measurements from the ERBE instrument, and also good agreement with the Sato et al. (1993) AOD timeseries beginning approximately 6 months after the eruption, especially with regard to the magnitude and seasonal variation of AOD. Furthermore, it was shown that model simulations of a Pinatubo-like eruption at two different longitudes resulted in no significant differences in AOD or SW anomalies.

In the MAECHAM5-HAM coupled aerosol-GCM, season of eruption plays a significant role in the space-time evolution of the AOD. Variations in the AOD pattern are qualitatively understandable in terms of seasonal variations in the BDC of the stratosphere, characterized by stronger poleward transport and mixing in the winter hemisphere. The BDC affects the timing and strength of transport of aerosols out of the tropics into mid- and high latitudes, leading to generally 
larger AODs in the hemisphere experiencing winter at the time of the eruption.

The sensitivity of AOD to eruption season, quantified as the percent difference between maximum and minium AOD, is weak in the tropics and generally increasing in strength towards the poles, with maximum sensitivity of around $75 \%$. We find that the seasonality of the BDC can affect not just the zonal mean AOD evolution, but also the global mean AOD. We found that eruptions in certain seasons led a smaller aerosol effective radius, which produced a stronger and longer lasting AOD. We hypothesize that seasonal variations in stratospheric dynamics, including tropical upwelling and horizontal transport out of the tropics affect the growth and lifetime of stratospheric aerosol particles. As a concrete example, in simulations of a Pinatubo-like eruption, an eruption in January led to a $\sim 25 \%$ larger global mean AOD than eruptions in other months. Future studies of the influence of stratospheric dynamics on aerosol formation and growth could be interesting with regards to both volcanic impacts and geoengineering.

One limitation of our study is that the model used does not exhibit a QBO, and instead has persitant easterly winds in the tropical stratosphere. The QBO influences tropical upwelling and the extratropical meridional transport of the BDC (Baldwin et al., 2001), and it has been shown that the QBO impacts the transport of volcanic aerosols from the tropics (Trepte and Hitchman, 1992) by modifying the amount of aerosol transported by the upper and lower branch of the BDC (Hitchman et al., 1994). In coupled aerosolGCM simulations of non-volcanic stratospheric background aerosol, it has been shown that the QBO influences aerosol concentration and size, in particular in the winter hemisphere (Hommel, 2008). Based on the results of our study, we hypothesize that variations in tropical upwelling associated with QBO might affect not just the horizontal transport of aerosols, but also their effective radius and hence lifetime, just as season of eruption did in our study. Testing this hypothsis while maintaining full feedbacks between aeorols and atmospheric dynamics would require coupling an aerosol microphysics module to a GCM with an internally generated QBO.

The influence of eruption season on AOD evolution is much stronger in the MAECHAM5-HAM simulations described here than was reported by Gao et al. (2008) based on a parameterized stratospheric transport scheme. The influence of season is a function of seasonal and hemispheric variations in stratospheric dynamics, therefore, the ability to accurately predict the influence of eruption season on volcanic impacts depends on accurate simulation of the dynamics of the stratosphere. Given the rather good agreement between observations and model simulated spatial and size evolution of volcanic aerosols after the 1991 Pinatubo eruption shown in Sect. 3, and prior validation of the underlying MAECHAM5 GCM (e.g., Manzini et al., 2006; Charlton et al., 2007; Thomas et al., 2009a,b), the results shown here suggest that the sensitivity to season of eruption is in reality stronger than suggested by the results of Gao et al. (2008).

In order to address how season of eruption impacts the resulting anomalies in solar shortwave (SW) radiation reaching the surface, we have examined both clear-sky and all-sky SW radiative flux anomalies. Clear-sky SW radiative flux anomalies are a function of the AOD and the seasonal cycle of solar insolation, and as a result, the general features (e.g., peaks, or hemispheric asymmetry) of the clear-sky SW anomalies may not be the same as that of the AOD field. The sensitivity of cumulative SW anomalies to eruption season is generally equal to or weaker than that of the AOD in midlatitudes and in the tropics, but can be stronger than that of the AOD in the high latitudes due to the strong seasonal cycle in solar insolation at high latitudes. In the global mean, clear-sky SW anomalies are less sensitive to eruption season than AOD, but still significantly greater than zero.

All-sky SW radiative flux anomalies are a function of the clear-sky SW radiative flux anomalies and the model clouds. We found that in the E17 experiment, differences in posteruption all-sky SW radiative flux anomalies between simulations with eruptions in different seasons were smaller than the natural variability of a control run, meaning that season of eruption would have a insignificant impact on all-sky SW radiative flux anomalies in any one simulation. These model results suggest that clouds are likely as important as season of eruption in determining the total radiative impact of a tropical volcanic eruption with magnitude comparable to Pinatubo.

We found that sensitivity to eruption season was different for two eruptions of widely differing $\mathrm{SO}_{2}$ injection magnitudes. Sensitivity of global mean AOD and clear-sky SW anomalies was found to be stronger, in relative terms, for the E17 experiment, with values on the order of $20 \%$, compared to $12-16 \%$ for the E700 experiment. This can be understood to be related to the fact that cross-equator transport was much more sensitive to season of eruption for the weaker eruption, leading to more variation in hemispheric asymmetry. We plan future sensitivity studies to examine in detail how the hemispheric asymmetry of aerosol transport depends on the magnitude and latitude of eruption, as well as the season. For example, since planetary-wave production and the BDC are generally stronger in the $\mathrm{NH}$, we would not expect the results shown here for an eruption at $15^{\circ} \mathrm{N}$ to be exactly comparable to an eruption at $15^{\circ} \mathrm{S}$.

While the impact of eruption season on all-sky SW anomalies was found to be insignificant for the E17 experiment, for the larger E700 eruption, global mean all-sky SW anomaly sensitivity is significantly greater than zero, and comparable to that of the other fields with a percent sensitivity of $16 \%$. This result underscores the fact that in order for differences in SW anomalies between different eruption months to be significant compared to the noise induced by clouds, the magnitude of the eruption needs to be quite large. Assessing the threshold, i.e., at what magnitude of $\mathrm{SO}_{2}$ injection is season of injection important for the surface SW impact, will be 
addressed in a future study by performing a number of simulations of magnitude between the E17 and E700 experiments considered here.

A larger than previously assumed sensitivity of AOD to eruption season result has implications for reconstructions of past volcanic forcing data sets. It implies that unless season of eruption can be deduced from the proxy records, then the choice of an arbitrary month of eruption can lead to uncertainty in the aerosol evolution. Based on the results of our model simulations, an unknown month of eruption could lead to uncertainties in global mean AOD larger than $20 \%$, and uncertainties in cumulative zonal mean AOD of greater than $50 \%$ in the mid- to high latitudes.

On the other hand, our model results imply that for Pinatubo-magnitude eruptions, variations in AOD based on season of eruption do not translate into significant differences in all-sky surface shortwave radiative anomalies. This is primarily due to the effects of clouds in the mid- to high latitudes, which greatly reduce the absolute difference in SW radiation between different eruption seasons, bringing such differences within the range of natural variability. This result implies that for Pinatubo-magnitude eruptions, the latitudinal morphology of the AOD pattern is not a critical factor for obtaining realistic cumulative SW flux anomalies at the surface, and therefore using an arbitrary month of eruption (e.g., Gao et al., 2008) or a scaled version of a Pinatubo-like AOD pattern (e.g., Robock et al., 2009; Harris and Highwood, 2011) for such eruptions in climate model simulations should likely produce no appreciable spatial bias in the surface all-sky SW radiation anomalies.

At eruption magnitudes larger than Pinatubo, differences in all-sky radiation brought about by differing season of eruption become significant: we found that for a near-super eruption, sensitivity to eruption season was significant for most latitudes, and in the global mean. Global mean all-sky SW anomalies showed a sensitivity to eruption season of approximately $18 \%$, with eruptions in solstice conditions (January and July) leading to largest anomalies. We also found that the space-time morphology of the AOD patterns for large magnitude eruptions were notably different than for a Pinatubo-like eruption, which implies that the use of a scaled Pinatubolike AOD pattern for super-eruptions (e.g., Robock et al., 2009; Harris and Highwood, 2011) may be unrealistic in terms of the spatial distribution of radiative anomalies at both the surface and in the stratosphere. This weakness of a scaled Pinatubo-like AOD pattern is in addition to the fact that it likely overestimates the cummulative radiative impact of very large eruptions since since it discounts the impact of aerosol size (e.g., Timmreck et al., 2010). Thus, for the reconstruction of past AOD for use in climate models, unknown season of eruption would be an appreciable source of uncertainty for large eruptions, although the size of this uncertainty is likely comparable or smaller than other uncertainties inherent in estimating AOD timeseries from paleo records (e.g., Robock and Free, 1995).
Some issues need to be considered when interpreting the sensitivity of SW anomalies shown here in terms of possible surface climate effects. Firstly, any changes in cloud fields brought about by the volcanic aerosol through mechanisms not included in the MAECHAM5-HAM could change the surface radiation budget sensitivity to season. For example, post eruption increases in cloud reflectivity due to volcanic aerosols acting as cloud condensation nuclei (Jensen and Toon, 1992) could conceivably affect the sensitivity to eruption season, although many studies (e.g., Wylie and Menzel, 1999; Luo, Z. et al., 2002) have reported no significant changes in cloud properties after the Pinatubo eruption. The decrease in sensitivity to eruption season of all-sky SW compared to clear-sky SW in our Pinatubo-magnitude experiment hints at a possible cloud feedback mechanism, however investigating such a possibility would require a more complex treatment of the interaction between clouds and volcanic aerosols (e.g., Lohmann, 2003). Secondly, it should be kept in mind that radiation anomalies do not necessarily translate directly into temperature anomalies since the thermal inertia of oceans dampens the surface temperature response to radiative anomalies.

Finally, it should be pointed out that dynamical responses to volcanic eruptions which can affect surface temperatures, for example the "winter warming phenomenon" (e.g., Robock, 2000), may be more sensitive to season of eruption than radiative fluxes. Comparison of our E17 and E700 simulation results shows that the dynamical effects of large eruptions, which produce significant heating of the tropical lower stratosphere, create much different aerosol transport patterns than weaker eruptions. It is likely that the induced polar vortices have significant effects on surface climate through dynamical coupling of the stratosphere and troposphere (e.g., Stenchikov, 2002). However, volcanic aerosol reconstructions which treat aerosols as passive tracers will not reproduce the type of aerosol evolution shown here. We conclude that in order for climate models with prescribed aerosol forcing to reproduce the most realistic radiative and dynamical perturbations resulting from very large volcanic eruptions, it may be necessary to use aerosol reconstructions which take into account the impact of aerosol heating on stratospheric dynamics.

Acknowledgements. This work has benefited greatly from stimulating discussions within the MPI-M Super Volcano project. The authors thank two anonymous reviewers for their helpful comments. This publication is contribution 219 of the Sonderforschungsbereich 574 "Volatiles and Fluids in Subduction Zones" at Kiel University. U. N. acknowledges funding by the FP7 project IMPLICC. Computations were performed at the German Climate Computer Center (DKRZ).

Edited by: E. Highwood 


\section{References}

Ammann, C. M., Meehl, G. A., Washington, W. M., and Zender, C. S.: A monthly and latitudinally varying volcanic forcing dataset in simulations of 20th century climate, Geophys. Res. Lett., 30, 1657, doi:10.1029/2003GL016875, 2003.

Baldwin, M. P., Gray, L. J., Dunkerton, T. J., Hamilton, K., Haynes, P. H., Randel, W. J., Holton, J. R., Alexander, M. J., Hirota, I., Horinouchi, T., Jones, D. B. A., Kinnersley, J. S., Marquardt, C., Sato, K., and Takahashi, M.: The quasi-biennial oscillation, Rev. Geophys., 39, 179, doi:10.1029/1999RG000073, 2001.

Barkstrom, B. R.: The Earth Radiation Budget Experiment (ERBE), Am. Meteorol. Soc., 65, 1170-1185, 1984.

Barkstrom, B. R. and Smith, G. L.: The Earth Radiation Budget Experiment: Science and implementation, Rev. Geophys., 24, 379, doi:10.1029/RG024i002p00379, 1986.

Bender, F. A.-M., Ekman, A. M. L., and Rodhe, H.: Response to the eruption of Mount Pinatubo in relation to climate sensitivity in the CMIP3 models, Clim. Dynam., 35, 875-886, doi:10.1007/s00382-010-0777-3, 2010.

Charlton, A. J., Polvani, L. M., Perlwitz, J., Sassi, F., Manzini, E., Shibata, K., Pawson, S., Nielsen, J. E., and Rind, D.: A New Look at Stratospheric Sudden Warmings. Part II: Evaluation of Numerical Model Simulations, J. Climate, 20, 470-488, doi:10.1175/JCLI3994.1, 2007.

Charney, J. G. and Drazin, P. G.: Propagation of Planetary-Scale Disturbances from the Lower into the Upper Atmosphere, J. Geophys. Res., 66, 83-109, doi:10.1029/JZ066i001p00083, 1961.

Fouquart, Y. and Bonnel, B.: Computations of solar heating of the earth's atmosphere: A new parameterization, Contrib. Atmos. Phys., 53, 35-62, 1980.

Gao, C., Robock, A., and Ammann, C.: Volcanic forcing of climate over the past 1500 years: An improved ice core-based index for climate models, J. Geophys. Res. Atmos., 113, D23111, doi:10.1029/2008JD010239, 2008.

Giorgetta, M. A., Manzini, E., Roeckner, E., Esch, M., and Bengtsson, L.: Climatology and Forcing of the Quasi-Biennial Oscillation in the MAECHAM5 Model, J. Climate, 19, 3882, doi:10.1175/JCLI3830.1, 2006.

Guo, S.: Re-evaluation of SO 2 release of the 15 June 1991 Pinatubo eruption using ultraviolet and infrared satellite sensors, Geochem. Geophys. Geosyst., 5, Q04001, doi:10.1029/2003GC000654, 2004a.

Guo, S.: Particles in the great Pinatubo volcanic cloud of June 1991: The role of ice, Geochem. Geophys. Geosyst., 5, Q05003, doi:10.1029/2003GC000655, 2004b.

Hamill, P., Jensen, E. J., Russell, P. B., and Bauman, J. J.: The Life Cycle of Stratospheric Aerosol Particles., B. Am. Meteorol. Soc., 78, 1395-1410, 1997.

Harris, B. M. and Highwood, E. J.: A simple relationship between volcanic sulfate aerosol optical depth and surface temperature change simulated in an atmosphere-ocean general circulation model, J. Geophys. Res., 116, D05109, doi:10.1029/2010JD014581, 2011.

Hitchman, M. H., McKay, M., and Trepte, C. R.: A climatology of stratospheric aerosol, J. Geophys. Res., 99, 20689-20700, doi:10.1029/94JD01525, 1994.

Holton, J. R., Haynes, P. H., McIntyre, M. E., Douglass, A. R., Rood, R. B., and Pfister, L.: Stratosphere-Troposphere Exchange, Rev. Geophys., 33, 403-439, doi:10.1029/95RG02097,
1995.

Hommel, R.: Die Variabilität von stratosphärischem HintergrundAerosol. Eine Untersuchung mit dem globalen sektionalen Aerosolmodell MAECHAM5-SAM2, Ph.D. thesis, University of Hamburg, Germany, 2008.

Hurrell, J. W., Hack, J. J., Shea, D., Caron, J. M., and Rosinski, J.: A New Sea Surface Temperature and Sea Ice Boundary Dataset for the Community Atmosphere Model, J. Climate, 21, 5145-5153, doi:10.1175/2008JCLI2292.1, 2008.

Jensen, E. J. and Toon, O. B.: The potential effects of volcanic aerosols on cirrus cloud microphysics, Geophys. Res. Lett., 19, 1759, doi:10.1029/92GL01936, 1992.

Kirchner, I., Stenchikov, G. L., Graf, H.-F., Robock, A., and Antuña, J. C.: Climate model simulation of winter warming and summer cooling following the 1991 Mount Pinatubo volcanic eruption, J. Geophys. Res., 104, 19039-19055, doi:10.1029/1999JD900213, 1999.

Kodera, K.: Influence of volcanic eruptions on the troposphere through stratospheric dynamical processes in the northern hemisphere winter, J. Geophys. Res., 99, 1273-1282, doi:10.1029/93JD02731, 1994.

Kodera, K. and Kuroda, Y.: Tropospheric and stratospheric aspects of the Arctic oscillation, Geophys. Res. Lett., 27, 3349, doi:10.1029/2000GL012017, 2000a.

Kodera, K. and Kuroda, Y.: A mechanistic model study of slowly propagating coupled stratosphere-troposphere variability, J. Geophys. Res., 105, 12361-12370, doi:10.1029/2000JD900094, 2000b.

Kokkola, H., Hommel, R., Kazil, J., Niemeier, U., Partanen, A.-I., Feichter, J., and Timmreck, C.: Aerosol microphysics modules in the framework of the ECHAM5 climate model - intercomparison under stratospheric conditions, Geosci. Model Dev., 2, 97-112, doi:10.5194/gmd-2-97-2009, 2009.

Kravitz, B. and Robock, A.: Climate effects of high-latitude volcanic eruptions: Role of the time of year, J. Geophys. Res., 116, D01105, doi:10.1029/2010JD014448, 2011.

Krüger, K., Tegtmeier, S., and Rex, M.: Variability of residence time in the Tropical Tropopause Layer during Northern Hemisphere winter, Atmos. Chem. Phys., 9, 6717-6725, doi:10.5194/acp-9-6717-2009, 2009.

Kutterolf, S., Freundt, A., and Peréz, W.: Pacific offshore record of plinian arc volcanism in Central America: 2. Tephra volumes and erupted masses, Geochem. Geophys. Geosyst., 9, Q02S02, doi:10.1029/2007GC001791, 2008a.

Kutterolf, S., Freundt, A., Peréz, W., Mörz, T., Schacht, U., Wehrmann, H., and Schmincke, H.: Pacific offshore record of plinian arc volcanism in Central America: 1. Alongarc correlations, Geochem. Geophys. Geosyst., 9, Q02S01, doi:10.1029/2007GC001631, 2008b.

Labitzke, K. and McCormick, M. P.: Stratospheric temperature increases due to Pinatubo aerosols, Geophys. Res. Lett., 19, $207-$ 210, doi:10.1029/91GL02940, 1992.

Lin, S.-J. and Rood, R. B.: Multidimensional FluxForm Semi-Lagrangian Transport Schemes, Mon. Weather Rev., 124, 2046-2070, doi:10.1175/15200493(1996)124<2046:MFFSLT>2.0.CO;2, 1996.

Lohmann, U.: Impact of the Mount Pinatubo eruption on cirrus clouds formed by homogeneous freezing in the ECHAM4 GCM, J. Geophys. Res., 108, 4568, doi:10.1029/2002JD003185, 2003. 
Luo, Z., Rossow, W. B., Inoue, T., and Stubenrauch, C. J.: Did the Eruption of the Mt. Pinatubo Volcano Affect Cirrus Properties?, J. Climate, 15, 2806-2820, doi:10.1175/15200442(2002)015<2806:DTEOTM>2.0.CO;2, 2002.

Manzini, E., Giorgetta, M. A., Esch, M., Kornblueh, L., and Roeckner, E.: The Influence of Sea Surface Temperatures on the Northern Winter Stratosphere: Ensemble Simulations with the MAECHAM5 Model, J. Climate, 19, 3863-3881, doi:10.1175/JCLI3826.1, 2006.

McIntyre, M. E. and Palmer, T. N.: Breaking planetary waves in the stratosphere, Nature, 305, 593-600, doi:10.1038/305593a0, 1983.

Mlawer, E. J., Taubman, S. J., Brown, P. D., Iacono, M. J., and Clough, S. A.: Radiative transfer for inhomogeneous atmospheres: RRTM, a validated correlated-k model for the longwave, J. Geophys. Res., 102, 16663-16682, doi:10.1029/97JD00237, 1997.

Niemeier, U., Timmreck, C., Graf, H.-F., Kinne, S., Rast, S., and Self, S.: Initial fate of fine ash and sulfur from large volcanic eruptions, Atmos. Chem. Phys., 9, 9043-9057, doi:10.5194/acp9-9043-2009, 2009.

Niemeier, U., Schmidt, H., and Timmreck, C.: The dependency of geoengineered sulfate aerosol on the emission strategy, Atmos. Sci. Lett., 12, 189-194, doi:10.1002/asl.304, 2010.

Perlwitz, J. and Graf, H.-F.: The Statistical Connection between Tropospheric and Stratospheric Circulation of the Northern Hemisphere in Winter., J. Climate, 8, 2281-2295, doi:10.1175/1520-0442(1995)008<2281:TSCBTA > 2.0.CO;2, 1995.

Randel, W. J., Garcia, R. R., and Wu, F.: Time-Dependent Upwelling in the Tropical Lower Stratosphere Estimated from the Zonal-Mean Momentum Budget, J. Atmos. Sci., 59, 2141-2152, doi:10.1175/1520-0469(2002)059<2141:TDUITT>2.0.CO;2, 2002.

Read, W. G., Froidevaux, L., and Waters, J. W.: Microwave limb sounder measurement of stratospheric $\mathrm{SO}_{2}$ from the Mt. Pinatubo Volcano, Geophys. Res. Lett., 20, 1299, doi:10.1029/93GL00831, 1993.

Robock, A.: Volcanic eruptions and climate, Rev. Geophys., 38, 191-220, doi:10.1029/1998RG000054, 2000.

Robock, A. and Free, M. P.: Ice cores as an index of global volcanism from 1850 to the present, J. Geophys. Res., 100, 1154911568, doi:10.1029/95JD00825, 1995.

Robock, A., Ammann, C. M., Oman, L., Shindell, D., Levis, S., and Stenchikov, G.: Did the Toba volcanic eruption of $\sim 74$ ka B.P. produce widespread glaciation?, J. Geophys. Res., 114, D10107, doi:10.1029/2008JD011652, 2009.

Roeckner, E., Baeuml, G., Bonaventura, L., Brokopf, R., Esch, M., Giorgetta, M., Hagemann, S., Kirchner, I., Kornblueh, L., Manzini, E., Rhodin, A., Schlese, U., Schulzweida, U., and Tompkins, A.: The atmospheric general circulation model ECHAM5 - Part I, Tech./ rep., MPI Report No. 349, 2003.

Rose, W., Newhall, C., Bornhorst, T., and Self, S.: Quaternary silicic pyroclastic deposits of Atitlán Caldera, Guatemala, J. Volcanol. Geotherm. Res., 33, 57-80, doi:10.1016/03770273(87)90054-0, 1987.

Rosenlof, K. H.: Seasonal cycle of the residual mean meridional circulation in the stratosphere, J. Geophys. Res., 100, 5173-5191, doi:10.1029/94JD03122, 1995.
Russell, P. B., Livingston, J. M., Pueschel, R. F., Bauman, J. J., Pollack, J. B., Brooks, S. L., Hamill, P., Thomason, L. W., Stowe, L. L., Deshler, T., Dutton, E. G., and Bergstrom, R. W.: Global to microscale evolution of the Pinatubo volcanic aerosol derived from diverse measurements and analyses, J. Geophys. Res., 101, 18745-18763, doi:10.1029/96JD01162, 1996.

Sato, M., Hansen, J. E., McCormick, M. P., and Pollack, J. B.: Stratospheric Aerosol Optical Depths, 18501990, J. Geophys. Res., 98, 22987-22994, doi:10.1029/93JD02553, with update retreived from data.giss.nasa.gov/modelforce/strataer, 1993.

Schmincke, H.-U.: Volcanism, Springer-Verlag, Heidelberg, Germany, p. 267, 2004.

Schoeberl, M. R. and Hartmann, D. L.: The dynamics of the stratospheric polar vortex and its relation to springtime ozone depletions., Science (New York, N.Y.), 251, 46-52, doi:10.1126/science.251.4989.46, 1991.

Self, S.: The effects and consequences of very large explosive volcanic eruptions., Philosophical transactions. Series A, Math. Phys. Eng. Sci., 364, 2073-2097, doi:10.1098/rsta.2006.1814, 2006.

Shindell, D. T., Schmidt, G. A., Miller, R. L., and Rind, D.: Northern Hemisphere winter climate response to greenhouse gas, ozone, solar, and volcanic forcing, J. Geophys. Res., 106, 7193 7210, doi:10.1029/2000JD900547, 2001.

Soden, B. J., Wetherald, R. T., Stenchikov, G. L., and Robock, A.: Global cooling after the eruption of Mount Pinatubo: a test of climate feedback by water vapor., Science (New York, N.Y.), 296, 727-730, doi:10.1126/science.296.5568.727, 2002.

SPARC CCMVal: SPARC Report on the Evaluation of ChemistryClimate Models, SPARC Report No. 5, WCRP-132, WMO/TDNo. 1526, 2010.

Stenchikov, G.: Arctic Oscillation response to the 1991 Mount Pinatubo eruption: Effects of volcanic aerosols and ozone depletion, J. Geophys. Res., 107, 4803, doi:10.1029/2002JD002090, 2002.

Stier, P., Feichter, J., Kinne, S., Kloster, S., Vignati, E., Wilson, J., Ganzeveld, L., Tegen, I., Werner, M., Balkanski, Y., Schulz, M., Boucher, O., Minikin, A., and Petzold, A.: The aerosolclimate model ECHAM5-HAM, Atmos. Chem. Phys., 5, 11251156, doi:10.5194/acp-5-1125-2005, 2005.

Thomas, M. A., Giorgetta, M. A., Timmreck, C., Graf, H.-F., and Stenchikov, G.: Simulation of the climate impact of Mt. Pinatubo eruption using ECHAM5 - Part 2: Sensitivity to the phase of the QBO and ENSO, Atmos. Chem. Phys., 9, 30013009, doi:10.5194/acp-9-3001-2009, 2009.

Thomas, M. A., Timmreck, C., Giorgetta, M. A., Graf, H.-F., and Stenchikov, G.: Simulation of the climate impact of Mt. Pinatubo eruption using ECHAM5 - Part 1: Sensitivity to the modes of atmospheric circulation and boundary conditions, Atmos. Chem. Phys., 9, 757-769, doi:10.5194/acp-9-757-2009, 2009. b.

Timmreck, C., Graf, H.-F., and Kirchner, I.: A one and half year interactive MA/ECHAM4 simulation of Mount Pinatubo Aerosol, J. Geophys. Res., 104, 9337-9359, doi:10.1029/1999JD900088, 1999.

Timmreck, C., Lorenz, S. J., Crowley, T. J., Kinne, S., Raddatz, T. J., Thomas, M. A., and Jungclaus, J. H.: Limited temperature response to the very large AD 1258 volcanic eruption, Geophys. Res. Lett., 36, L21708, doi:10.1029/2009GL040083, 2009.

Timmreck, C., Graf, H.-F., Lorenz, S. J., Niemeier, U., Zanchettin, 
D., Matei, D., Jungclaus, J. H., and Crowley, T. J.: Aerosol size confines climate response to volcanic super-eruptions, Geophys. Res. Lett., 37, L24705, doi:10.1029/2010GL045464, 2010.

Trepte, C. R. and Hitchman, M. H.: Tropical stratospheric circulation deduced from satellite aerosol data, Nature, 355, 626-628, doi:10.1038/355626a0, 1992.

Vignati, E.: M7: An efficient size-resolved aerosol microphysics module for large-scale aerosol transport models, J. Geophys. Res., 109, D22202, doi:10.1029/2003JD004485, 2004.

Waugh, D. W.: Seasonal variation of isentropic transport out of the tropical stratosphere, J. Geophys. Res., 101, 4007-4023, doi:10.1029/95JD03160, 1996.

Wielicki, B. A., Wong, T., Allan, R. P., Slingo, A., Kiehl, J. T., Soden, B. J., Gordon, C. T., Miller, A. J., Yang, S.-K., Randall, D. A., Robertson, F., Susskind, J., and Jacobowitz, H.: Evidence for large decadal variability in the tropical mean radiative energy budget., Science, New York, NY, USA, 295, 841-844, doi:10.1126/science.1065837, 2002.
Wong, T., Wielicki, B. A., Lee, R. B., Smith, G. L., Bush, K. A., and Willis, J. K.: Reexamination of the Observed Decadal Variability of the Earth Radiation Budget Using Altitude-Corrected ERBE/ERBS Nonscanner WFOV Data, J. Climate, 19, 40284040, doi:10.1175/JCLI3838.1, 2006.

Wylie, Donald P. and Menzel, W. Paul: Eight Years of High Cloud Statistics Using HIRS, J. Climate, 12, 170-184, 1999.

Young, R. E., Houben, H., and Toon, O. B.: Radiatively forced dispersion of the Mt. Pinatubo volcanic cloud and induced temperature perturbations in the stratosphere during the first few months following the eruption, Geophys. Res. Lett., 21, 369372, doi:10.1029/93GL03302, 1994. 